\title{
Meso-Analysis of Crack Propagation in Loess under Lateral Unloading Action
}

\author{
Chuanshan Pang ${ }^{1}$, Hongjun Jing ${ }^{2,3}$, Xihao Dong ${ }^{2}$, and Panteng Zhang ${ }^{2, *}$ \\ ${ }^{1}$ Shaanxi Water Affair Group Co., Ltd, Xian 710068, China \\ ${ }^{2}$ College of Architecture \& Civil Engineering, Xi' an University of Science and Technology, Xian 710054, China \\ ${ }^{3}$ Researcher Center of Road Engineering, Xi'an University of Science and Technology, Xian 710054, China
}

Received 3 March 2020; Accepted 27 April 2020

\begin{abstract}
Crack development in loess is an important factor for loess collapse, while cut slope unloading accelerates crack development in loess. However, the macroscopic loess reaction characteristics and meso-structural changes under unloading action have not been systematically and comprehensively explained yet. A lateral unloading test of undistributed loess samples was conducted through GDS unsaturated soil triaxial instrument to simulate the load-carrying path of loess during the loess slope excavation process, followed by analysis via CT scanning image analysis technique. This test aims to explore crack propagation laws in loess and the propagation mechanism under lateral unloading action. Test results indicate that, 1) Numerous cracks appear inside the loess samples after complete failure due to the weakening and strengthening of loess and frictional strength, respectively; 2) Elastic deformation decreases while elastoplastic and plastic deformations increase with the unloading rate. The crack propagation in loess is evident and the CT number and its variance are large when the unloading capacity and rate are substantial. The variable quantity is gradually reduced from the outer ring toward the center; 3) With the increase in unloading capacity, the CT number changes from an increasing into a declining trend, while the change trend of the CT number variance is the opposite; 4) Large coarse cracks are developed after unloading under low moisture content, but microcracks are relatively developed under high moisture content; 5) As the moisture content increases, the variable quantity of the CT number is enlarged while that of its variance is reduced. This study can provide a reference for understanding the propagation of joint cracks on loess cut slope under unloading action.
\end{abstract}

Keywords: Slope project, Loess, Lateral unloading, Crack, CT scanning

\section{Introduction}

Slope toes are usually cut to enlarge the area of construction land during construction activities of industrial and civil use, such as plants, bases, and cave dwellings, or during road engineering and water engineering construction processes due to special topographic conditions in loess areas. Because of cut slope unloading, abrupt cliffs several and even dozens of meters in height and even high and steep slopes hundreds of meters in height are formed. Thus, the original stress state inside slope loess is changed and passive soil pressure is weakened. Stress is released after slope cutting to cause rebound loess deformation. Unloading cracks are developed on excavation faces and at slope tops. Under comprehensive actions of rainwater infiltration and freeze-thaw cycles, unloading cracks are continuously stretched outward, water infiltrates along joints, and the strength of loess joint crack faces is weakened. Under the gravitational effect, increasing cracks will have a direct impact on slope deformation and failure, easily resulting in loess collapse disaster, severely endangering all kinds of engineering construction and the safety of people's lives and properties, and restricting sustainable local economic development [1-2]. Therefore, reasonably recognizing the crack evolution laws in loess under loading action is necessary to obtain a deep understanding of propagation mechanisms of joint cracks

*E-mail address: 810056071@qq.com

ISSN: $1791-2377 @ 2020$ School of Science, IHU. All rights reserved.

doi:10.25103/jestr.133.21 under unloading actions of loess cut slopes.

Considering the propagation mechanism of joint cracks induced by loess unloading, investigations conducted by domestic and foreign experts and scholars have mainly focused on impacts of foundation pit and tunnel excavation on clay [3], silty clay [4-5], and soft soil. Meanwhile, only a few investigations have involved slope excavation and the impact of excavation on loess. Most investigations have concentrated on the mechanical properties of loess while providing less attention to crack propagation laws in loess under meso-conditions. The mechanism studies on loess collapse disasters are directly effected by insufficient cognition of loess damage propagation process, deformation failure mode, and crack development laws under unloading action and a fuzzy understanding of internal structural change in loess under unloading action of cut slopes. These conditions introduce difficulties to engineering site selection and construction in loess areas and disaster prevention and mitigation in the operation process.

Thus, correctly understanding the impact of unloading action of cut slope on loess strength, especially the relationship between unloading characteristics of cut slope and joint crack propagation in loess and the joint crack propagation mechanism under this unloading action, is crucial. The meso- and micro-structural change laws in loess before and after unloading under different unloading conditions are proposed in this study, and the crack propagation laws in loess under lateral unloading action are investigated. 


\section{State of the art}

Physical and mechanical properties of loess present complex changes under unloading action. Domestic and foreign scholars have performed numerous investigations through theoretical analysis, experimental study, and numerical simulation considering the stress-strain relation curves of partial loess under different unloading stress paths. However, these investigations have concentrated on the impacts of foundation pit and tunnel excavation on soft clay, red clay, and other soil masses mainly from a macroscopic angle. For instance, $\mathrm{Li}$ et al. analyzed the impact of stress paths on the unloading response of foundation pits [6]. Maleki et al. studied the influence of stress paths on baseplates and wall deformations of foundation pits [7]. Zhang et al. conducted a series of experimental studies on stress-strain relation curves, strength and deformation characteristics, and failure characteristics under different unloading stress paths through experiments, focusing on the impact of loading path on the final result [8]. Based on the triaxial unloading creep test, Huang et al. believed that the unloading creep of soft soil was divided into three phases, namely decay, steady, and accelerated creep, and behaviors were impacted by deviatoric stress and time [9]. They further discussed the influences of pore water pressure and unloading rate on the mechanical properties of soft clay and proposed that unloading action was destructive due to low confining pressure and high pore water pressure [10]. Peng et al. proposed that different excavation conditions exerted important controlling effects on loess slopes and introduced the proposed unloading constitutive model based on the stress path test to simulate lateral and bottom loess deformations in the loess slope excavation area [11]. In the deformation analysis of excavation conditions, Lim et al. indicated that if undrained shear strength and unloading/reloading modulus were accurately determined, even the Mohr-Coulomb model could effectively predict the wall deflection of deep foundation pits [12]. The abovementioned studies have analyzed the impacts of foundation pit and tunnel excavation on soft and red clay from a macroscopic angle. However, investigations on loess collapse disaster caused by the unloading action of cut slope and the development of cracks and holes inside loess before and after unloading at the meso-level are lacking. Hence, further studying the physical and mechanical properties of loess before and after unloading is necessary.

The studies on the physical and mechanical properties of loess have already been systematic and mature, but the results have mainly involved macroscopic stability problems, such as loess collapsibility [13], freeze-thaw damage [14], rheological properties [15], and unsaturation characteristics [16-17]. However, a few studies have probed into joint cracks in loess and the physical and mechanical properties of loess before and after unloading. Most of these studies have focused on controlling matric suction and confining pressure as variables. For instance, Tang et al. divided slope joint development into collapsible, tensile, compressive, and excavation unloading joint development zones [18]. Through an experimental study, $\mathrm{Li}$ et al. found that the stress-strain curve of unsaturated $\mathrm{Q}_{3}$ loess presented hardening type under lateral unloading and increased yield stress with suction and net consolidated confining pressure [19]. Zhang et al. conducted the neural network prediction of loess strength under unloading stress paths based on test results [20]. The above studies mainly explored the shear strength and macroscopic stability of loess. However, comprehensive investigations on the relationship between mechanical properties of loess and loess collapse disasters must still be implemented. The influence laws of unloading rate, unloading capacity, and moisture content on crack propagation in loess have also been scarcely reported. The stress-strain relations of loess under different unloading rates and capacities require further investigation.

In addition to macro-property studies, meso-damage mechanics, such as CT scanning image, have become crucial, and the corresponding results have been recognized by the engineering and academic fields. Chung et al. applied CT to all kinds of cement-based materials and studied internal structures of materials to evaluate their performances [21]. Watanabe et al. developed a new type of soil particle tracking method, wherein CT scanning images could be used to evaluate the displacement of sandy soil under triaxial compression [22]. Sato et al. observed the internal structure of rock samples through CT and evaluated porosity distribution to analyze the pore structure and permeability performance of shales [23]. Although the application of the CT detection technique to loess studies is remarkably late, this technique is still suitable for the special material, that is, loess. For instance, Li et al. used CT to scan undisturbed Malan loess samples and quantified structural parameters of macropores [24]. Ye et al. conducted processing and analysis of CT images based on pseudo-color enhancement technique, defined damage variables, and quantitatively evaluated damage states of loess samples [25]. The above studies can qualitatively reflect internal crack and hole development in soil samples before and after unloading from the meso-level and quantitatively reflect sectional structural characteristics of soil samples. Therefore, meso-mechanics can be employed to examine the physical and mechanical changes in unsaturated loess under different unloading paths to reveal its intrinsic nature from a certain dimensional level. The macroscopic characteristics and meso-structural changes in rock soil can be associated through macro- and mesoexperimental studies.

Hence, considering the deficiencies in the existing studies, GDS unsaturated soil triaxial instrument is used in the current study to conduct lateral unloading tests of unsaturated loess under different unloading rates, unloading capacities, and moisture contents. On this basis, secondary stress change characteristics of loess slope excavation are also observed and analyzed. CT scanning images are combined to study the unloading-induced crack propagation laws of unsaturated loess, stress-strain relation curves of loess under different unloading conditions, and change laws of strength parameters, explore the influence characteristics of unloading rate and capacity on the mechanical strength of loess, and discuss the crack evolution laws in loess under unloading action.

The remainder of this study is organized as follows. Section 3 expounds on the experimental design. Section 4 explores the stress-strain characteristics of loess samples according to test results and analyzes crack propagation laws and mechanisms under different unloading capacities, unloading rates, and moisture contents. The final section summarizes this study and provides related conclusions.

\section{Methodology}

\subsection{Test loess samples}

$\mathrm{Q}_{3}$ unsaturated loess samples were taken from typical loess collapse points on tableland in Luochuan developed with 
Chuanshan Pang, Hongjun Jing, Xihao Dong and Panteng Zhang./

Journal of Engineering Science and Technology Review 13 (3) (2020) 191 - 199

unload-induced cracks. These samples were s yellowishbrown without stratification but with vertical joints, the soil texture was uniform, wormholes were observed, and macropores were found locally. White calcareous concretion, which was slightly wet and presented a hard plastic state, was also observed. The physical property indexes of the loess samples are listed in Table 1.

Table.1. Physical property indexes of loess samples

\begin{tabular}{|c|c|c|c|c|c|c|}
\hline Index & $\begin{array}{l}\text { Moisture } \\
\text { content }(\%)\end{array}$ & $\begin{array}{l}\text { Density } \\
\left(\mathrm{g} / \mathrm{cm}^{3}\right)\end{array}$ & Porosity & $\begin{array}{l}\text { Liquid } \\
\text { limit (\%) }\end{array}$ & $\begin{array}{l}\text { Plastic } \\
\text { limit (\%) }\end{array}$ & $\begin{array}{l}\begin{array}{l}\text { Relative } \\
\text { density }\end{array} \\
\end{array}$ \\
\hline $\mathrm{lu}$ & 13.2 & 1.43 & 1.15 & 20.6 & 31.2 & 2.72 \\
\hline
\end{tabular}

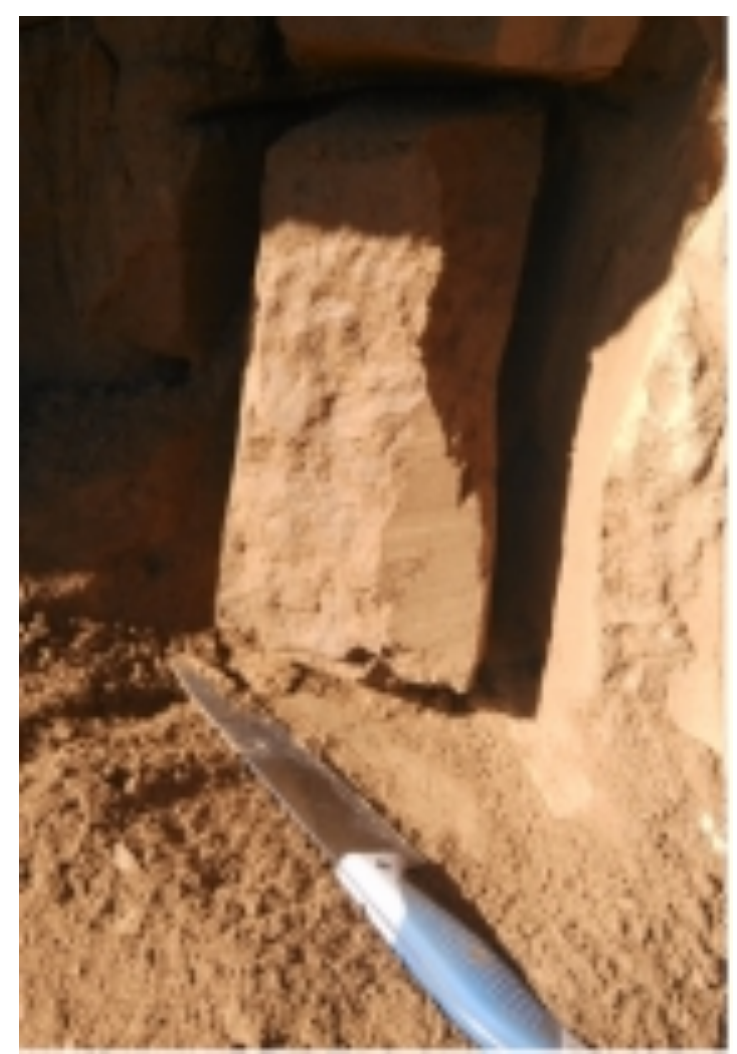

Fig. 1. Unsaturated loess samples obtained from the field

\subsection{Testing equipment}

The equipment used in the unloading test was GDS unsaturated soil triaxial testing system (Fig. 2 (a)) from Xi'an University of Science and Technology. Researched and developed by Geotechnical Digital System Instruments Ltd (UK), this instrument can complete saturated and unsaturated soil static triaxial tests under multiple stress paths.

The CT scanning equipment was SIEMENS SOMATOM plus X-ray spiral CT machine (Fig. 2 (b)) from the State Key Laboratory of Frozen Soil Engineering in Cold and Arid Regions Environmental and Engineering Research Institute, Chinese Academy of Sciences This equipment possesses the following characteristics: resolution of 0.35 $\mathrm{mm} \times 0.35 \mathrm{~mm}$, minimum identifiable volume of $0.12 \mathrm{~mm}^{3}$ (layer thickness: $1 \mathrm{~mm}$ ), density contrast resolution of $0.3 \%$, scanning thickness of $5 \mathrm{~mm}$, scanning time of $2 \mathrm{~s}$, scanning voltage of $120 \mathrm{kV}$, current of $165 \mathrm{~mA}$, post-positioning amplification coefficient of 10.0, and normal temperature of at $20{ }^{\circ} \mathrm{C}$. This $\mathrm{CT}$ scanning was divided into the initial scanning phase and the scanning phase after the unloading test. The middle section of each loess sample was scanned and its position was marked.

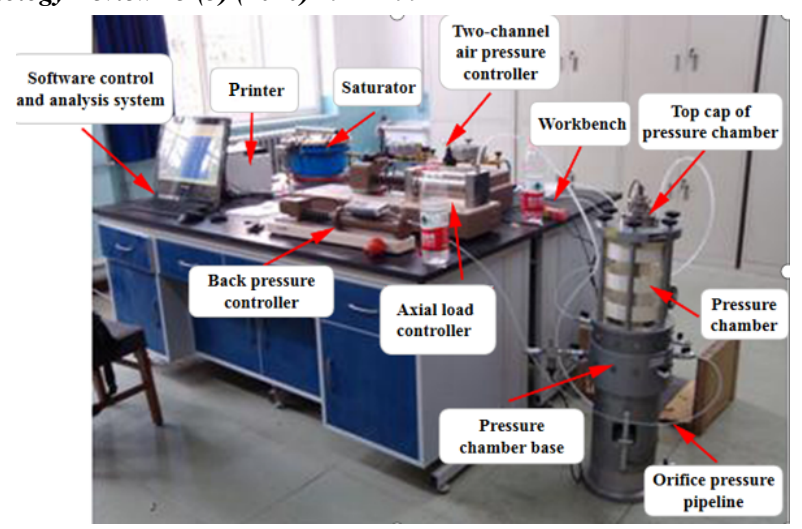

(a)

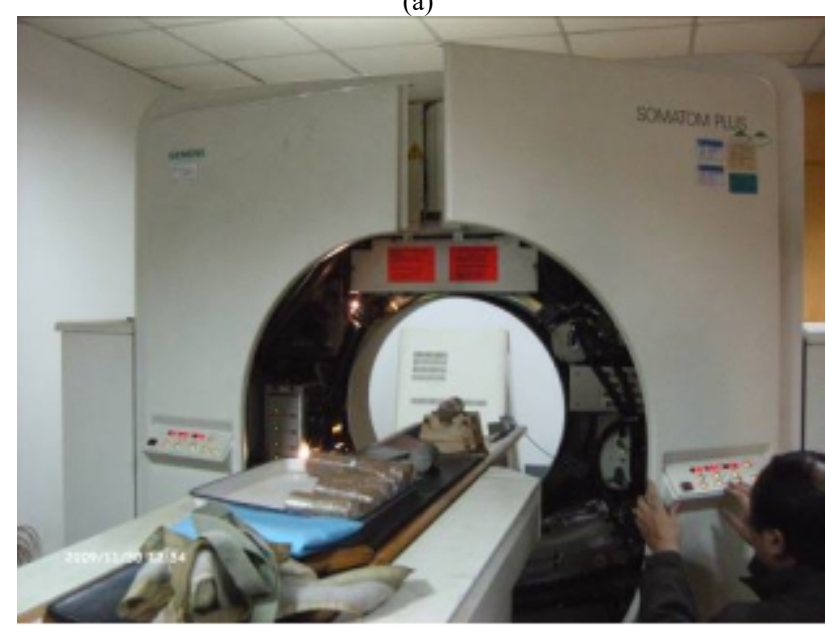

(b)

Fig. 2. Instrument and equipment. (a) GDS unsaturated soil triaxial instrument. (b) CT scanner.

\subsection{Test steps}

Loess samples were prepared in the laboratory to conduct lateral unloading and CT scanning tests of the samples. The test steps were as follows.

(1) $\varphi 39.1 \mathrm{~mm} \times 80 \mathrm{~mm}$ unsaturated loess samples were prepared in the laboratory. Samples with different moisture contents ( $\omega=7 \%, 13 \%, 18 \%, 22 \%$, and $27 \%$ ) were prepared using natural drying and artificial wetting methods and then grouped and numbered.

(2) Initial CT scanning of central sections $(0.5 \mathrm{~h})$ of the samples was conducted, and initial scanning positions were marked with a marking pen.

(3) Isobaric consolidation of the samples was implemented under $500 \mathrm{kPa}$ confining pressure. Afterward, axial pressure was kept unchanged to perform lateral unloading at a certain rate $(0.01,0.02,0.04$, and 0.08 $\mathrm{kPa} / \mathrm{min})$. The test would end when the loading capacity reached 50,100 , and $150 \mathrm{kPa}$ and until complete failure of the samples.

(4) CT scanning was performed again for post-unloading samples, and scanning positions were consistent with initial scanning positions.

Each scanned section was zoned (Fig. 3): from section center to edge were center, middle ring, and outer ring successively and two synthetic zones, namely large and whole zones; large zone was the sum of center and middle rings, and whole zone was the sum of center, middle ring, and outer ring. The loess sample was $\varphi 39.1 \mathrm{~mm} \times 80 \mathrm{~mm}$ in size in the initial scanning phase, and the corresponding area of the whole zone was $12.00 \mathrm{~cm}^{2}$. The diameter and area of 
center were $1.60 \mathrm{~cm}$ and $1.96 \mathrm{~cm}^{2}$, respectively; those of large zone were $2.90 \mathrm{~cm}$ and $6.50 \mathrm{~cm}^{2}$ respectively; and those of the middle ring were $4.54 \mathrm{~cm}$ and $5.50 \mathrm{~cm}^{2}$, respectively.

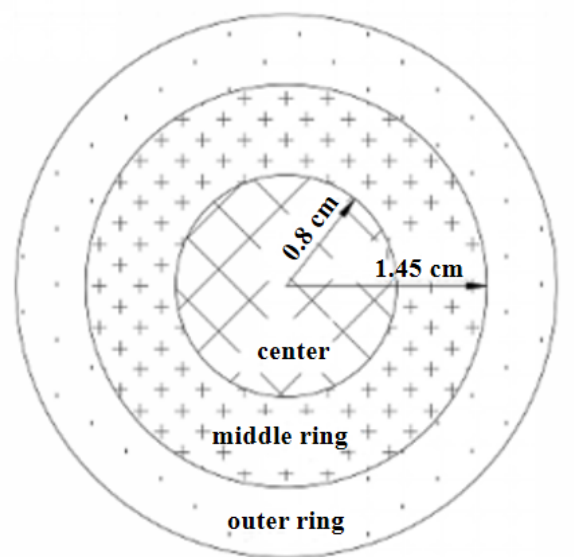

Fig. 3. Zoning graph of scanning section

4. Test results and analysis

\subsection{Stress-strain characteristic research}

The stress-strain relation curves of the loess sample $(\omega=$ 13\%) in Fig. 4 were drawn under different unloading rates and capacities. The test results showed that the elastic deformation of the sample was decreased as the unloading rate increased, but elastoplastic and plastic deformations were enlarged. The stress-strain relation presented a linear segment under an unloading capacity of approximately 50 $\mathrm{kPa}$. This finding indicates that the loess was still under elastic deformation, which could be different under various unloading rates. The slope of the linear segment increased with the unloading rate, while its elastic deformation presented the opposite tendency. As the unloading capacity $(100 \mathrm{kPa})$ was continuously elevated, the loess sample underwent elastoplastic deformation. This deformation was respectively small and large under high and low unloading rates. When the unloading capacity reached $150 \mathrm{kPa}$, the loess sample under high unloading rate remained in the plastic deformation phase but that under low unloading rate already entered the plastic deformation phase. When the sample underwent complete failure, the stress-strain relation curve was weak hardening type and could be largely divided into the following three deformation phases: elastic, elastoplastic, and plastic. Furthermore, when the unloading rate is high, the elastic deformation is small and the elastoplastic and plastic deformations are large.

Fig. 4 shows that the shear stress of loess samples increased with the unloading rate. The influence of the unloading rate on loess strength comprised weakening and strengthening of loess and frictional strengths, respectively. The deterioration and strengthening degrees of material and frictional strength, respectively, could exert different impacts under different unloading rates. Under high unloading rates, the loess sample had no sufficient time to experience plastic deformation, and its deformation tended to be localized with elasticity. That is, elastic deformation was enlarged, plastic deformation was postponed, and the loess strength was correspondingly elevated. In addition, under high unloading rate, pore water pressure in the loess sample could not be rapidly dissipated during the shear process. Thus, pore water pressure was formed at a local part inside the loess sample, and loess strength would be strengthened.

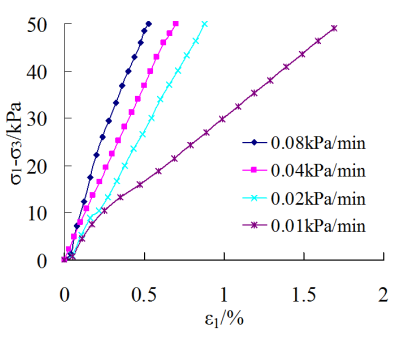

(a)

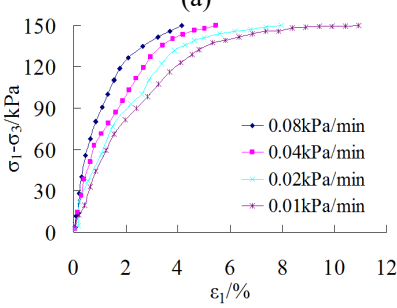

(c)

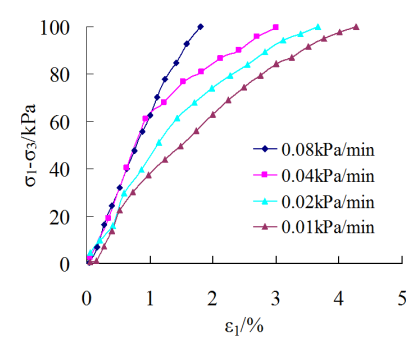

(b)

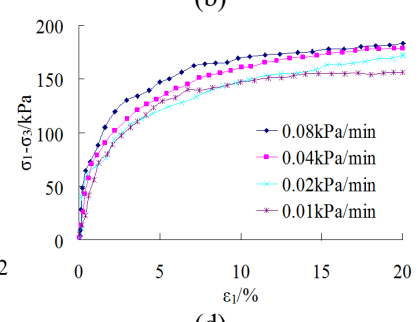

(d)
Fig. 4. Stress-strain relation curves. (a) $50 \mathrm{kPa}$. (b) $100 \mathrm{kPa}$. (c) $150 \mathrm{kPa}$. (d) Complete failure.

\subsection{Crack propagation laws and mechanism research}

\subsubsection{Crack propagation laws and mechanism in loess} under different unloading capacities

CT scanning images could qualitatively reflect the development of cracks and holes inside loess samples from the meso-level. Meanwhile, the quantitative reflection of sectional structural characteristics of loess samples could be completed by CT number and its variance. The sectional density of loess increased with CT number, and internal nonuniformity of loess and development degrees of cracks and holes presented positive correlations with the variance of the CT number.

Through the $\mathrm{CT}$ scanning test, $\mathrm{CT}$ scanning results of loess samples ( $\omega=13 \%, \Delta \mathrm{q}=0.08 \mathrm{kPa} / \mathrm{min})$ before and after unloading under different unloading capacities were acquired (Fig. 5). According to CT scanning images before unloading, many pores, cracks, and large loess particle aggregates existed in the samples. These media were under disordered distribution with non-uniform sizes, the connection between particles and that between particle and cement were weak, and many microcracks were distributed at particle boundary. These findings indicate that important initial meso-structures were formed at the particle boundary of the loess samples, generating initial damages with remarkably strong non-uniformity. For example, CT numbers of four samples in initial scanning were 1084.98, 1083.53, 1095.84, and 1084.62.Thus, the samples were slightly similar in overall density. However, CT number varied from zone to zone, where CT number of central zone was the minimum, followed by that of middle and outer rings. This finding indicates that sample density was gradually reduced from inside to outside possibly because of disturbance caused by sample preparation to loess samples. The variance of CT number could also be different in various zones in the same section of each loess sample, where the variance in the central zone was minimum, followed by that in large and whole zones successively. Thus, internal structures of loess samples, especially pore size and position, were different under the initial state. Under small unloading capacity (50 and $100 \mathrm{kPa}$ ), the mesostructural changes in loess samples were not observed before and after the test, and CT numbers in all zones were slightly enlarged. However, the increment amplitudes of CT number in the zones were different, where the increasing amplitude 
Chuanshan Pang, Hongjun Jing, Xihao Dong and Panteng Zhang./

Journal of Engineering Science and Technology Review 13 (3) (2020) 191 - 199

in the center was the minimum, followed by that in the middle and outer rings. The unloading capacity reached 150 $\mathrm{kPa}$, microcracks appeared in loess samples, and their CT numbers were reduced in comparison with those before unloading. The unloading capacity was continuously enlarged until complete failure, a thorough crack approximately $46 \mathrm{~mm}$ in length and $2.5 \mathrm{~mm}$ in width appeared, CT numbers in the outer and middle rings were reduced, and the reduction amplitudes of CT numbers in different zones were varied. The reduction amplitudes in the outer and middle rings were respectively large and small. The variance of $\mathrm{CT}$ number declined as the unloading capacity was reduced; that is, original holes and cracks were compressed tightly under pressure action. The variance of CT number was gradually enlarged with the unloading capacity.

Overall, cracks would appear inside loess only when a certain unloading capacity was reached. Each loess sample remained in the elastic deformation phase under small unloading capacity, internal loess structure was undamaged, and consolidated compression generated to the loess sample under the action of consolidated confining pressure was the primary cause for meso-structural change. Moreover, as confining pressure was directly applied to the edge of loess samples, the stress in the central zone was gradually increased. This increase led to the maximum and minimum compaction degrees in the outer ring and the center, respectively. In addition, given that confining pressure and moisture content were small, internal structural change in loess samples was small, and CT number and its variable presented minor changes. The stress-strain curves (Fig. 4) show that the loess sample was turned from elastic into elastoplastic deformation as the unloading proceeded. Given that the unloading capacity was small while confining pressure was relatively high, plastic deformation inside the loess was mainly due to local stress concentration, and the arrangement order of some particles was adjusted where the loess particles were weakly bonded. When the unloading capacity reached a certain value, the stress state requirement could not be reached by adjusting the order of loess particles, a large quantity of energy aggregated inside the loess would be released by tearing the loess. These conditions lead to crack propagation and penetration. During the unloading process, internal lateral stress was gradually reduced from the edge to the center of the loess, loess particles or aggregates underwent axial movement from two ends to the middle under the action of axial compression, and radial movement was observed from the center to the edge. The loess in the outer ring was under the action of tensile stress, while the central loess remained in the compaction state under the action of axial stress. Therefore, the reduced amplitude of the CT number in the outer ring was larger than that in the middle ring, while the $\mathrm{CT}$ number in the central zone was enlarged.
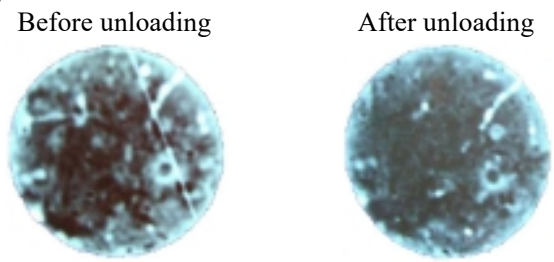
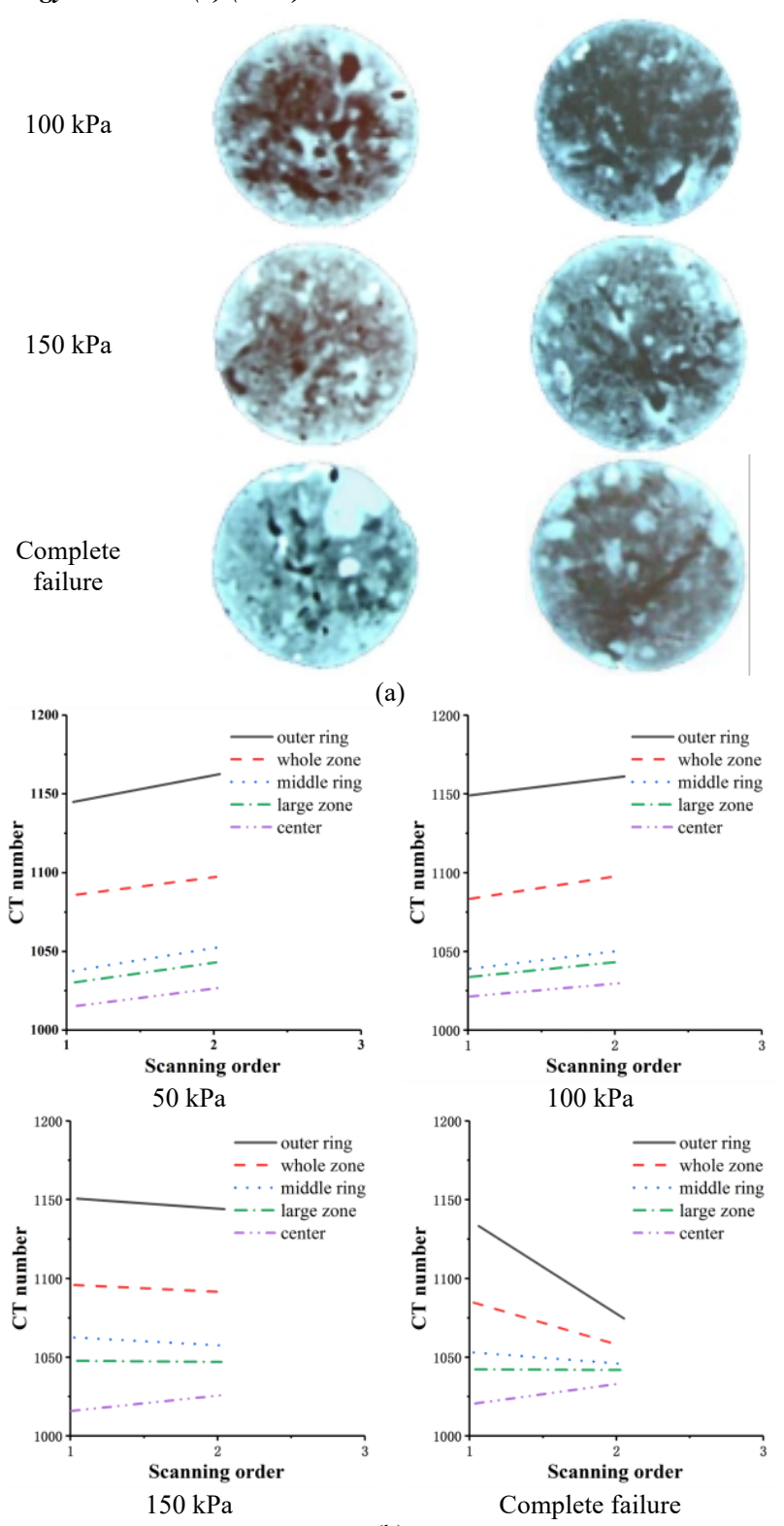

(b)
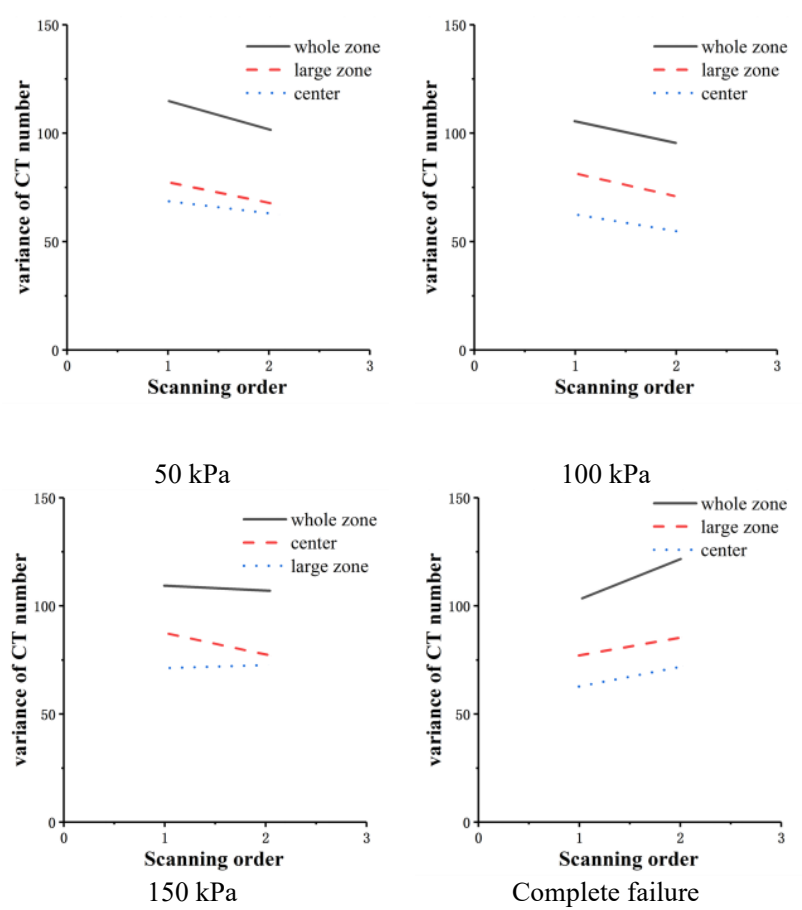
Chuanshan Pang, Hongjun Jing, Xihao Dong and Panteng Zhang./

Journal of Engineering Science and Technology Review 13 (3) (2020) 191 - 199

(c)

Fig. 5. CT scanning results of loess samples before and after unloading under different unloading capacities. (a) CT scanning images. (b) Change in CT number. (c) Variance change in CT number.

\subsubsection{Crack propagation laws and mechanism in loess samples under different unloading rates}

Fig. 6 displays CT scanning results of loess samples $(\omega=$ $13 \%$, complete failure) before and after unloading under different unloading rates. CT scanning images in Fig. 6 (a) reveal that the crack propagation in each sample became evident as the unloading rate increased. Under low unloading rate, microcracks, which were narrow and short, were well developed and mainly distributed at the edge. The crack width was large nearby the edge; the crack width was small when it was close to the center. Moreover, cracks presented staggered distribution with dendritic shape, and the crack propagation evolved from the edge toward the center. Fig. 6 (b) shows that the CT numbers in the middle and outer rings in each loess sample were decreased after the unloading test, the CT number in the center was enlarged, and the variable quantity of CT numbers could be different under various unloading rates; that is, the variable quantity increased with unloading rate. The variable quantity of the CT number was different in various zones, wherein the variable quantity in the center was the minimum, followed by those in the middle and outer rings. Fig. 6 (c) shows that the variable quantity of CT number variance increased with unloading rate; otherwise, the variable quantity would be reduced.

Overall, a high unloading rate results in remarkable crack propagation. The impact of unloading rates on crack propagation loess samples was related to particle movement in the shear process. That is, loess particles underwent relative movement under the action of unloading stress and presented radial and axial movements from the center to the edge and from two ends to the center, respectively. Under low unloading rate, loess particles had sufficient time to move, and the density difference between various zones inside the loess sample was small. Thus, the change in CT number was relatively small. The concentrated stress generated at the tip under crack propagation could be rapidly weakened through relative movement between particles. When defects, such as pores and holes, were encountered in crack propagation, concentrated stress at the tip was further weakened. Thus crack width was generally small. As the unloading proceeded, cracks started propagation in new directions, causing a curved crack shape. The energy aggregated at the crack tip was transferred to loess particles to overcome resistance and generate movement. Consequently, the deformation of loess samples, which was manifested by plastic flow failure from the macroscopic level, was large. Under high unloading rates, the concentrated stress at the tip of internal cracks could not be absorbed by loess particles within a short time, and the energy was mainly released through crack propagation. Thus, crack propagation was aggravated, and crack width and length were enlarged. As loess particles had insufficient time to move under high unloading rate, the amount of movement was small, the order could not be fully adjusted, the variable quantity of crack propagation direction was relatively small, and crack shape was smooth. Furthermore, during the unloading process, the peripheral stress was first released, and loess particles rapidly moved toward the edge of the loess sample. Similarly, loess particles in the center also had insufficient time to move. Consequently, the variable quantity of the central density was minimum, followed by those in the center and outer rings successively.

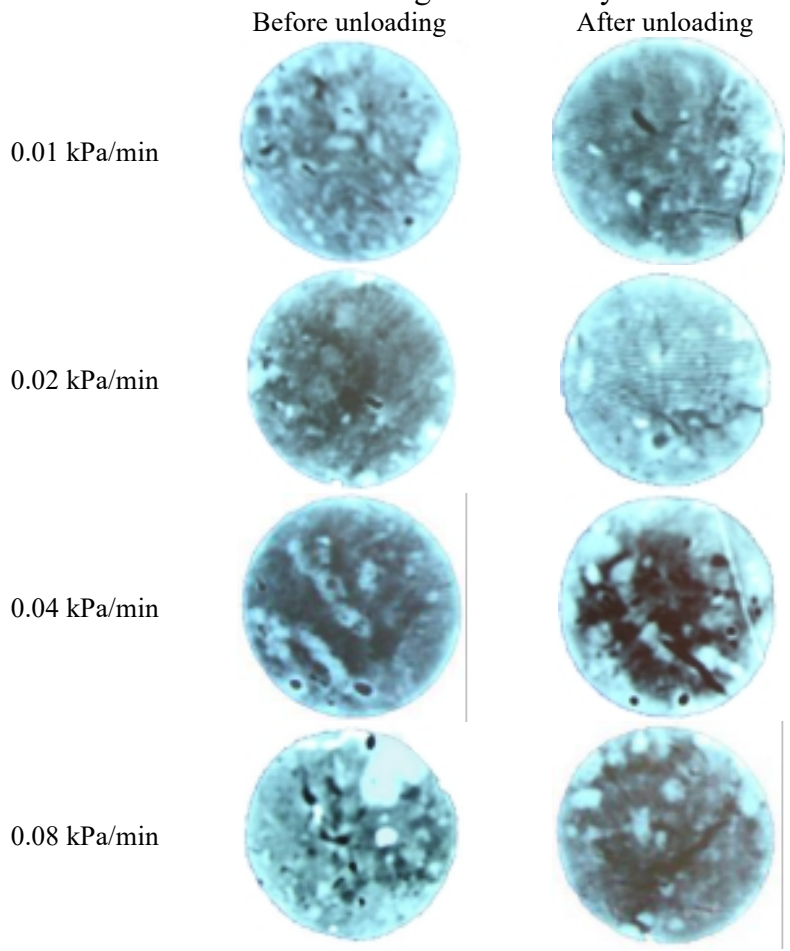

(a)
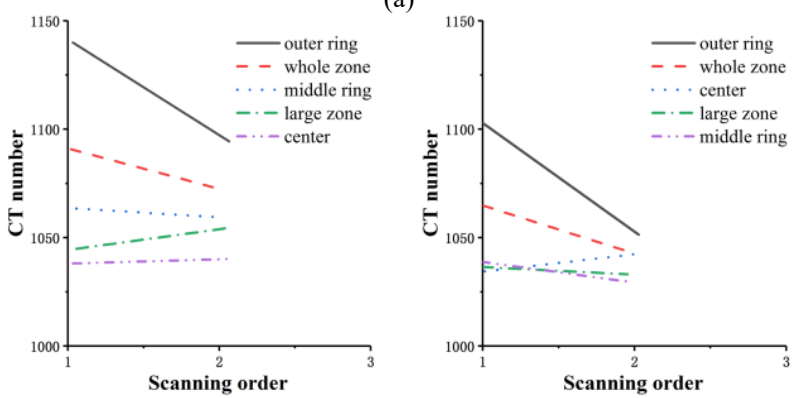
$\Delta \mathrm{q}=0.01 \mathrm{kPa} / \mathrm{min}$
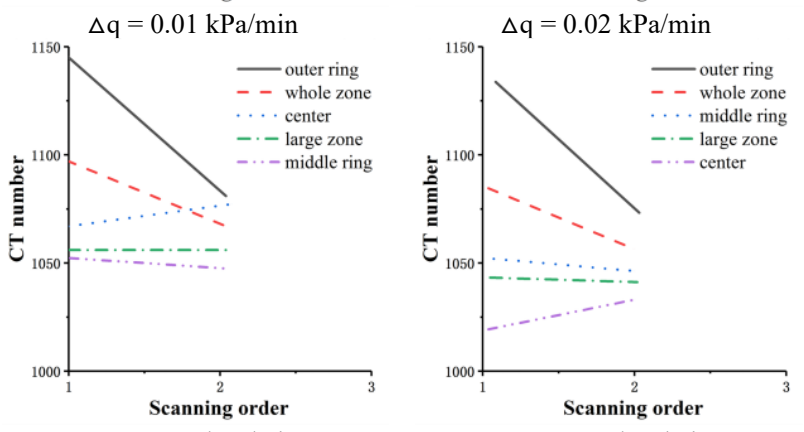

$\Delta \mathrm{q}=0.04 \mathrm{kPa} / \mathrm{min}$

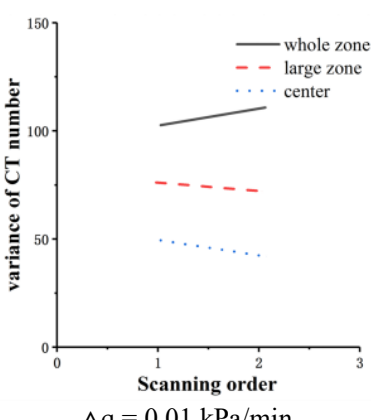

(b)

$\Delta \mathrm{q}=0.08 \mathrm{kPa} / \mathrm{min}$

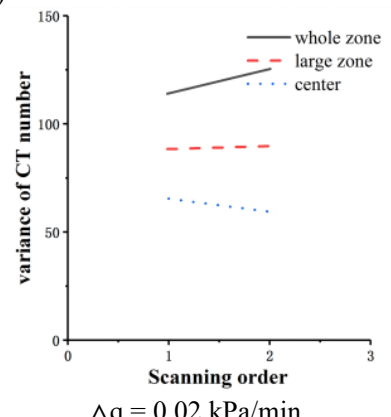


Chuanshan Pang, Hongjun Jing, Xihao Dong and Panteng Zhang./

Journal of Engineering Science and Technology Review 13 (3) (2020) 191 - 199
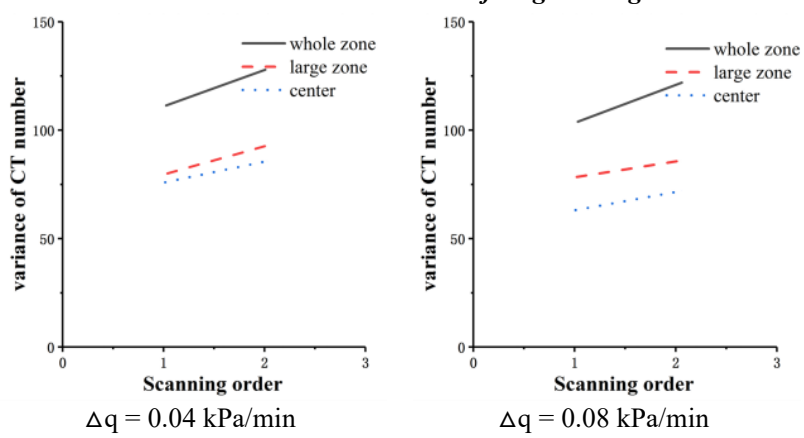

(c)

Fig. 6. CT scanning results of loess samples before and after unloading under different unloading rates. (a) CT scanning images. (b) Change in $\mathrm{CT}$ number. (c) Variance change in CT number.

4.2.3 Crack propagation laws in loess samples with different moisture contents and propagation mechanisms The CT scanning results of loess samples with different moisture contents before and after unloading $\left(\sigma_{\mathrm{ic}}=200 \mathrm{kPa}\right.$, $\Delta \mathrm{q}=0.08 \mathrm{kPa} / \mathrm{min}$, complete failure) are displayed in Fig. 7. Fig. 7 (a) shows the presence of numerous cracks inside the loess sample with large crack width under low moisture content $(\omega=7 \%)$. These cracks were mutually staggered. As the moisture content was increased $(\omega=18 \%)$, shear failure zone, sectional cracks, and a few holes appeared inside the loess sample, the internal shear zone was observed, and the loess inside the shear zone loosened. When moisture content $\mathrm{w} \geq 22 \%$, microcracks were considerably developed inside the loess sample. However, coarse cracks could be hardly observed because cracks were mainly distributed in the middle and outer rings with small length and width and are crossed. Under different moisture contents, the CT numbers in the outer ring, middle ring, and other samples were respectively reduced after unloading, enlarged, and decreased. The CT number in the central position and its variance were enlarged. Moreover, the variable quantity of the CT number was increased but that of the CT number variance was reduced with the increase in moisture content.

The analysis results show the following: loess strength was high under low moisture content; the deformation was small during the unloading process; the energy aggregated in loess was rapidly released; crack propagation was evident; wide and large cracks were quite developed and mostly presented brittle failure; most loess skeleton structures were undamaged or slightly damaged, except for those nearby cracks; density change in all zones was minor, thus indicating the relatively small degree of the CT number variation. Under high moisture content, water weakened the bonding strength between particles and the cementation effect between loess particles. During the unloading process, most of the original structures inside loess were slightly or completely damaged, loess particles could move freely, large deformation was observed, and plastic flow failure usually occurred. Consequently, many microcracks were found, and CT number demonstrated numerous changes before and after unloading.

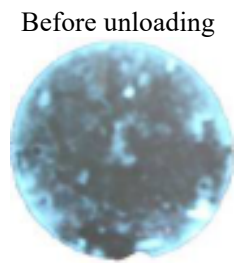

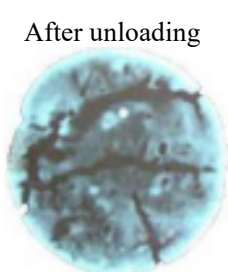

$18 \%$

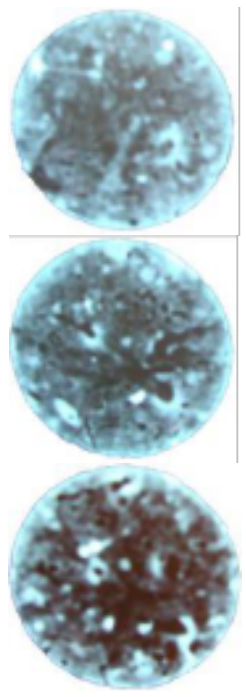

(a)
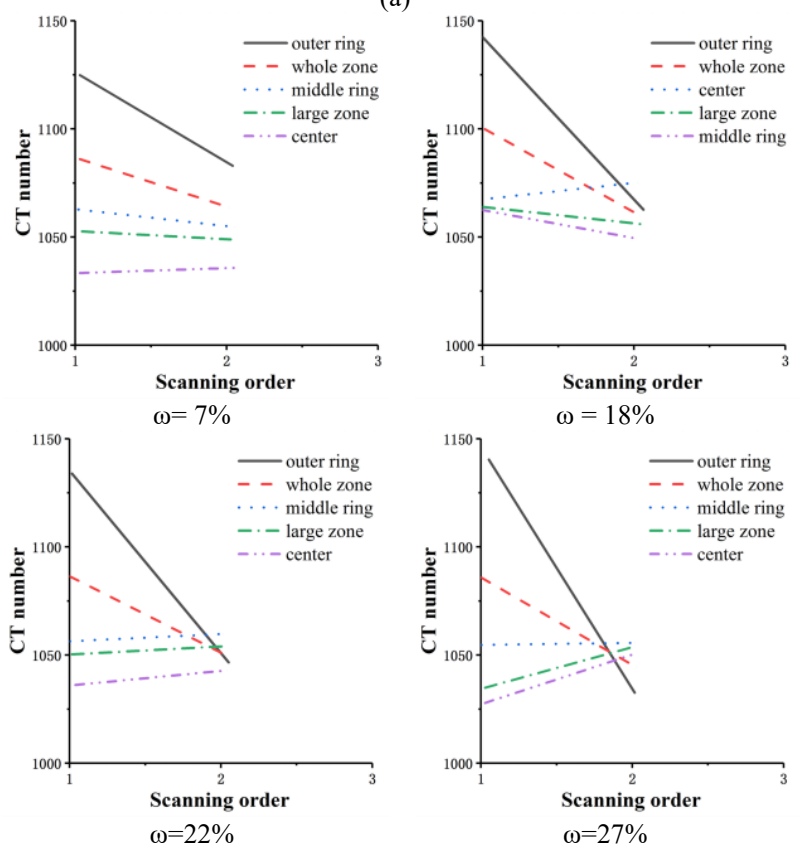

(b)
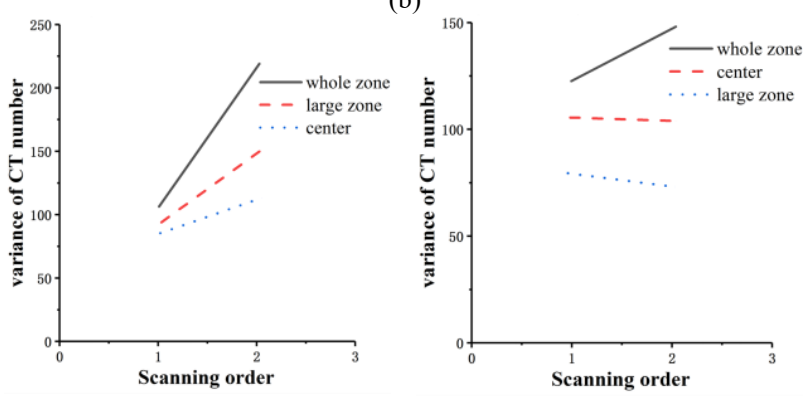

$\omega=7 \%$
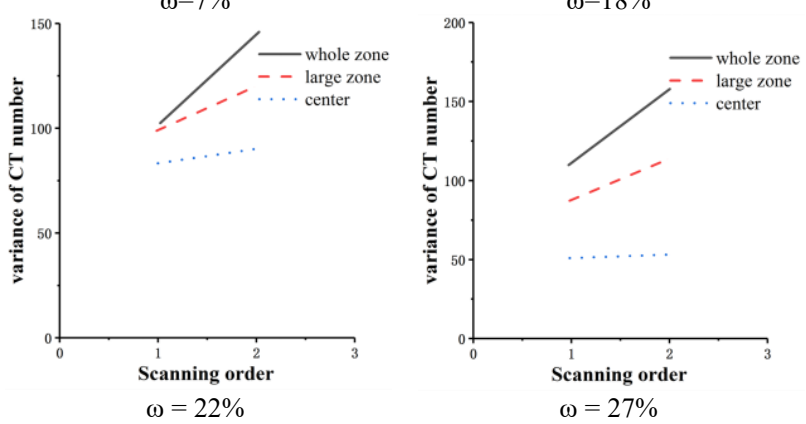

(c)

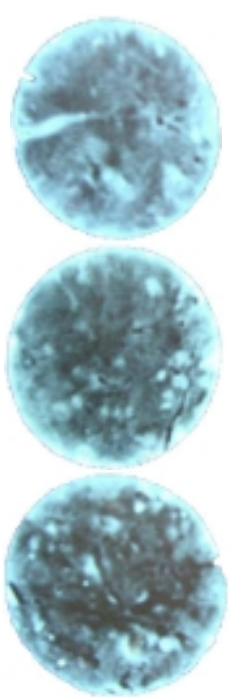

\section{西}


Chuanshan Pang, Hongjun Jing, Xihao Dong and Panteng Zhang./

\section{Journal of Engineering Science and Technology Review 13 (3) (2020) 191 - 199}

Fig. 7. CT scanning results of loess samples with different moisture contents before and after unloading. (a) CT scanning images. (b) Change of CT number. (c) Variance change in CT number.

\section{Conclusions}

A conventional triaxial shear test was conducted in this study to explore the crack propagation laws in loess under the lateral unloading action. GDS unsaturated soil triaxial instrument was used to simulate unloading stress paths in loess under different conditions. The meso-structural changes inside loess samples before and after unloading were also observed with a CT scanner. The following conclusions were mainly drawn.

(1) Sample deformation largely undergoes three phases, namely elastic, elastoplastic, and plastic phases, with the increase in unloading capacity. A large quantity of cracks appears in the loess after complete failure due to the weakening of loess strength and the strengthening of frictional strength. Elastic deformation is reduced as the unloading rate increases. However, elastoplastic deformation, plastic deformation, and shear stress showed an increasing tendency.

(2) Initial damage exists in the loess under natural state with remarkably strong non-uniformity. In the initial unloading phase, holes and cracks inside the loess are compacted tightly. After a certain unloading capacity is reached, cracks are generated, propagated, and interpenetrated as this capacity increases. The CT number is then turned from an increasing tendency into a declining tendency. However, the change in variance of the CT number presents an opposite tendency.

(3) CT number and its variance are increased with the unloading rate, and crack propagation becomes evident.
Wide and large cracks are quite developed under low moisture content. Meanwhile, microcracks are well developed under high moisture content. CT numbers of loess samples in the outer ring are reduced after unloading under different moisture contents; those in the middle ring of some loess samples are increased while those of other samples are reduced. CT number and variance in the central position are enlarged. The variable quantity of the CT number is increased, while that of CT number variance is reduced with the increase in moisture content.

The crack propagation laws in loess samples under the lateral unloading action, which are summarized in this study through the above analysis, can provide a reference for understanding joint crack propagation under unloading actions of cut loess slopes. Although some beneficial results have been achieved, these results are far from sufficient for the comprehensive examination of the formation mechanism of loess collapse due to the restricted ability level of the authors, limited time, and test conditions. Thus, other influence factors must be further investigated.

\section{Acknowledgments}

The authors are grateful for the support provided by the National Natural Science Foundation of China (Grant Nos. 41672305 and 41902299) and the Shaanxi Key R\&D Project (Grant No. 2017ZDXM-SF-082).

This is an Open Access article distributed under the terms of the Creative Commons Attribution License

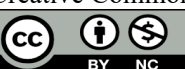

\section{References}

1. Liu, D. S., "Loess and environment". Beijing: Science Press, China, 1985 , pp.5-481.

2. Zhang, Z. H., "Chinese Loess". Beijing: Geological Publishing House, China, 1989, pp.2-336.

3. Shi, J. W., Ding, C., C.W.W. Ng, et al., "Effects of overconsolidation ratio on tunnel responses due to overlying basement excavation in clay". Tunnelling and Underground Space Technology, 97(3), 2020, pp.103247.

4. Kim, K., Rutqvist, J., Birkholzer, J., "Lattice modeling of excavation damage in argillaceous clay formations: Influence of deformation and strength anisotropy". Tunnelling and Underground Space Technology, 98(4), 2020, pp. 103196.

5. Liu, B., Zhang, D. W., Yang, C., et al, "Long-term performance of metro tunnels induced by adjacent large deep excavation and protective measures in Nanjing silty clay". Tunnelling and Underground Space Technology incorporating Trenchless Technology Research, 95(1), 2020, PP. 103147.

6. Li, X., Cao, W., Zhou, Z., et al, "Influence of stress path on excavation unloading response". Tunnelling and Underground Space Technology, 42(5), 2014, PP.237-246.

7. Shams, M. Y., Khazaei, J., "A Numerical Comparison of the Behavior of a Braced Excavation Using Two and ThreeDimensional Creep Plastic Analyses". Geotechnical and Geological Engineering, 35 (5), 2017, PP.2017-2035.

8. Zhang, M. X., Sun, J., "Unloading-induced deformation and strength properties of loess during construction". Chinese Journal of Rock Mechanics and Engineering, 24(13), 2005, PP.2248-2254.

9. Huang, W., Wen, K., Li, D., et al, "Experiment Study of Lateral Unloading Stress Path and Excess Pore Water Pressure on Creep Behavior of Soft Soil". Advances in Civil Engineering, 2019(3), 2019, PP.1-9.

10. Huang, W., Wen, K. J., Liu, D. Y., et al, "Experimental study on influence of excess pore water pressure and unloading ratio on unloading mechanical properties of marine sedimentary soft soils". Ocean Engineering, 195(1), 2020, PP.1-9.
11. Peng, J. B., Fan, Z. J., Wu, D., et al, "Landslides triggered by excavation in the loess plateau of China: A case study of Middle Pleistocene loess slopes". Journal of Asian Earth Sciences, 171(11), 2019, PP.246-258.

12. Lim, A., Ou, C. Y., "Stress paths in deep excavations under undrained conditions and its influence on deformation analysis". Tunnelling and underground space technology, 63(3), 2017, PP.118-132.

13. Arya, A. L., Samson, N., Ian, S., "Loess as a collapsible soil: Some basic particle packing aspects". Quaternary International, 469(3), 2018, PP.20-29.

14. Xu, J., Ren, J., Wang, Z., et al, "Strength behaviors and mesostructural characters of loess after freeze-thaw". Cold Regions Science and Technology, 148, 2018, PP.104-120.

15. Wang, X. G., Wang, J. D., Zhan, H. B., et al, "Moisture content effect on the creep behavior of loess for the catastrophic Baqiao landslide". Catena, 187(4), 2020, PP.104371.

16. Yates, K., Fenton, C. H., Bell, D. H., "A review of the geotechnical characteristics of loess and loess-derived soils from Canterbury, South Island, New Zealand”. Engineering Geology, 236(3), 2018, PP.11-21.

17. Ng, C. W. W., Mu, Q. Y., Zhou, C., "Effects of soil structure on the shear behaviour of an unsaturated loess at different suctions and temperatures". Canadian Geotechnical Journal, 54(2), 2017, PP.270-279.

18. Tang, D. Q., Yao, X. F., Peng, J. B., "Loess Joints Development Characteristics and Space Partition". Applied Mechanics and Materials, 501-504, 2014, PP.312-317.

19. Li, J. G., Chen, Z. H., Huang, X. F., et al, "CT-triaxial shear tests on the meso-structure evolution and strength of unsaturated loess $\mathrm{Q}_{3}$ during unloading confining pressure". Rock and Soil Mechanics, 31(04), 2010, PP.1084-1091.

20. Zhang, M. X., Min, X., Tu, M., "Predicting strength of loess under unloading stress paths with neural networks". Rock and Soil Mechanics, 2004(S2), 2004, PP.85-88. 
Chuanshan Pang, Hongjun Jing, Xihao Dong and Panteng Zhang./

Journal of Engineering Science and Technology Review 13 (3) (2020) 191 - 199

21. Chung, S. Y., Kim, J. S., Stephan, D., et al., "Overview of the use of micro-computed tomography (micro-CT) to investigate the relation between the material characteristics and properties of cement-based materials". Construction and Building Materials, 229(12), 2019, PP.116843.

22. Watanabe, Y., Lenoir, N., Otani, J., et al., "Displacement in sand under triaxial compression by tracking soil particles on X-ray CT data". Soils and Foundations, 52(2), 2012, pp.312-320.

23. Sato, A., Obara, Y., "Analysis of Pore Structure and Water Permeation Property of a Shale Rock by Means of X-Ray CT". Procedia Engineering, 191(5), 2017, pp.666-673.
24. Li, X., Lu, Y., Zhang, X., et al., "Quantification of macropores of Malan loess and the hydraulic significance on slope stability by Xray computed tomography”. Environmental Earth Sciences, 522(8), 2019, pp.1-19.

25. Ye, W. J., Li, C., "The consequences of changes in the structure of loess as a result of cyclic freezing and thawing". Bulletin of Engineering Geology and the Environment, 78(4), 2019, PP.21252138 . 